Doutora em Comunicação e Semiótica pela PUC-SP. Professora do Centro de Artes e Arquitetura da Universidade de Caxias do Sul. Coordenadora de especializações lato sensu na área da Moda na UCS. Autora

de Sensacional da moda (Educs, 2002) e coorganizadora das publicações Palavra prima: as faces de Chico

Buarque (Educs, 2006) e Tropicália: gêneros, identidades, repertórios e linguagens(Educs, 2008), entre outras.

\title{
Sustentabilidade: uma prática no ensino de moda
}

\section{Sustainability:}

\section{a practice in fashion education}

[resumo] 0 presente artigo tem como objetivo relatar a prática desenvolvida na disciplina Gerência de Produto de Moda, do curso de Tecnologia em Moda e Estilo, da Universidade de Caxias do Sul. A tarefa final da disciplina pretende oferecer ao aluno a oportunidade de vivenciar todo o processo de desenvolvimento de uma coleção de moda. Para tanto, mediante um case, os estudantes, reunidos em grupo, devem planejar, organizar, dividir responsabilidades, controlar as atividades conforme o cronograma acertado anteriormente e, finalmente, avaliar os resultados. 0 case, fornecido no segundo semestre de 2008 , foi sobre sustentabilidade. A partir de roupas usadas, os alunos tiveram que desenvolver uma coleção para ser comercializada. 0 trabalho foi um desafio, considerando que "o novo" é o grande valor na moda. 0 artigo descreve os 70 dias e os 12 encontros da disciplina focados no case. 0 objetivo foi atingido com sucesso.

\section{palavras-chave}

moda; sustentabilidade; método de ensino.

[abstract] This article has the purpose of reporting the experience developed in the course Management of Fashion Product. This course is part of the curriculum of Fashion Design Program at Universidade de Caxias do Sul. The final work for this course intends to make the students experience the whole process of developing a fashion collection. A case is given, students work as a team; they have to plan, organize, share responsabilities, control the activities as scheduled previously, and finally evaluate the results. The case given, in the second school semester of 2008 was about sustainability. The students had to make a fashion collection to be commercialized, with second hand clothes. The work was a challenge, considering that "nouveau" is the biggest value in fashion. This article describes 70 days and 12 meetings of the course focus on the case. The objective was achieved with success.

[key words] fashion; sustainability; teaching method. 
0 Case

Uma questão que preocupa toda a sociedade, desde políticos eminentes até crianças do Ensino Fundamental, é a sustentabilidade. Por isso ela deve estar na agenda de qualquer setor produtivo. No decorrer do século XX, a moda incorporou essa temática e presenciou mudanças significativas no setor.

$\mathrm{Na}$ crescente urbanização da Europa Ocidental e das Américas, ocorrida a partir do século XIX até a década de 1960, impôs-se o paradigma da produção seriada na indústria têxtil, que produzia quantidades a bom preço para a população trabalhadora crescente.

Satisfeita a demanda dentro do contexto de bem utilitário, a indústria têxtil, mais especificamente o vestuário, volta sua atenção aos novos valores da moda: novidade, sedução e desenvolvimento de marca. Os valores simbólicos das roupas passam a predominar para a classe média emergente da sociedade de consumo, a partir dos anos 1960. A lógica da obsolescência programada, que move a moda desde então, infiltra-se em outros produtos e só cresce nas economias capitalistas. 0 novo deve ser consumido para dar conta da produtividade alcançada pela tecnologia e pela eficiência atingida na gestão industrial. 0 fora de moda é desvalorizado pela crescente noção de obsolescência percebida no meio social.

Na Austrália, por exemplo, as novas tecnologias e técnicas (bio, nano, digital e outras) aplicadas aos têxteis suscitam problemas de ordem prática para a indústria da moda, alertam Farren e Hutchison (2004). Surgem daí algumas questões polêmicas, como: de que modo a possibilidade de um vestuário tecnologicamente orientado afetará a prática da indústria e o consumo de novidades da moda de maneira geral?

A tecnologia de roupas, relacionada ao vestuário, constitui, segundo Farren e Hutchison (2004), o conjunto de razões para que a moda se torne cada vez mais uma questão de praticidade e conforto, deixando de ser tão somente uma questão de estilo. A preocupação desses pesquisadores em sinalizar a crescente importância da tecnologia dos têxteis diante do estilo, da sedução das roupas, pode resultar numa redução do acelerado consumo de novidades da moda. Isso é um problema para as sociedades capitalistas devotas do consumo. E também para a moda que Lipovetsky afirmou ser "a pedra angular das sociedades democráticas voltadas para a produção-consumo-comunicação de massa" (1989, p. 12).

Ao fator tecnologia dos têxteis e das roupas, devem-se agregar os parâmetros da moda sustentável, ou seja, o consumo consciente, o valor do reciclado, o valor do artesanato, o slow design, que é a desaceleração associada ao consumo responsável, a qual promove a inovação. Assim, o pensamento criativo do design torna-se o caminho potencial para mudanças em escala global, completa Mau (2006).

Hoje a cultura consumista é uma realidade, mas está sendo questionada por muitos formadores de opinião, desde sociólogos e ambientalistas até os profissionais e pesquisadores de moda. Surgem defensores de um consumo consciente, os quais entendem a sustentabilidade ambiental, social e econômica como problema planetário, sem fronteiras.

Nos meios de comunicação, no documentário de Al Gore, no documentário de Leonardo Di Caprio e no braço da ONG e-brigade ${ }^{1}$ está o e-fabric ${ }^{2}$ que se preocupa com produção têxtil ecossustentável. Além disso, são empresas grandes como Malwee, Marisol, Petenatti, Sultextil, Hering e muitas outras do segmento têxtil que levam a bandeira da sustentabilidade. A iniciativa da Federação das Indústrias do Estado do Rio Grande do Sul (FIERGS) - chamada Banco do Vestuário - também é providencial, pois designa um setor da federação como responsável pelo recebimento de roupas em desuso e pelo novo destino a ser dado a elas.

Na Inglaterra, Nick Knight, um dos mais influentes fotógrafos de moda do mundo, acreditando que a moda é intrinsecamente política, propôs o projeto Political Fashion. Convidou indústrias de moda, artistas plásticos, figuras célebres para expor, por meio de filmes de formatos múltiplos, suas crenças, seus pensamentos, seus planos sobre moda. ${ }^{3}$ Muitos trabalhos são de alerta ou de contestação à cultura do consumo e à exploração humana ou ambiental, em nome de fetiches, luxos, marcas, padrão de beleza, novidades, enfim, exageros da moda.

A renomada e internacionalmente conhecida marca Diesel lançou campanhas publicitárias alertando para catástrofes advindas do aquecimento global (global 
warming ready, 2007) e para o stress da acelerada vida contemporânea (live fast, 2008). Isso pode ser uma estratégia de marketing, talvez uma banalização dos problemas, mas, de qualquer forma, essas campanhas endossam a sustentabilidade como tema relevante na atualidade.

A tomada de consciência relativa à preservação do meio ambiente e do homem, depois de catástrofes ambientais e de problemas como poluição atmosférica, é ampla e geral. Essa conscientização levou ao crescimento das ecoproduções, do biodiesel, da agricultura orgânica, das reciclagens, dos créditos de carbono, enfim do mercado verde. Não só as empresas, o marketing, os meios de comunicação e os governos estão na cena, mas principalmente as escolas e as universidades envolvem-se na mudança de costumes para salvar o planeta.

Assim, os cursos de Moda das instituições de ensino superior precisam engajar-se na conscientização da realidade atual da moda e do consumo e repensar o valor novidade, buscando alternativas sustentáveis. A moda é, na sua essência, uma indústria de consumo acelerado.

A ideia é apropriar-se dos "erres" da sustentabilidade: reduzir o consumo tanto dos recursos naturais como das fontes de energia; reciclar os resíduos têxteis; reutilizar 0 que ainda pode ser útil, prolongando o ciclo de vida dos produtos; e, ainda, redescobrir os conhecimentos e sabedorias tradicionais (artesanatos) e incorporá-los à tecnologia.

Com o conhecimento desses fatos, o desafio foi lançado: os alunos da disciplina Gerência de Produto de Moda, do segundo semestre de 2008, deveriam se organizar em grupos de até seis participantes e pensar uma maneira de desenvolver um trabalho criativo de moda através de minicoleções de caráter comercial, baseado nos "erres" da sustentabilidade. A saber: reduzir, reciclar, reutilizar e redescobrir.

\section{Encontro: da teoria à pratica}

Foram apresentados exemplos e imagens de várias empresas e ONGs ligadas ao setor têxtil, que estavam desenvolvendo projetos de sustentabilidade social, ambiental e/ou econômica. Essas ações têm conquistado a simpatia dos consumidores e a qualidade de "politicamente corretas", entre as quais destacam-se:

- S4, tendências sustentáveis na moda é um projeto que, desde 2006, vem sendo desenvolvido pela modelo e ativista Summer Rayne Oakes ${ }^{4}$. 0 projeto elege quatro qualidades para as roupas da indústria da moda, são elas: substance, sexiness, style, sustainability (substância, sensualidade, estilo e sustentabilidade). A carta compromisso do S4 é dirigida à indústria da moda, que deve estreitar suas inter-relações com o homem e o meio ambiente. Alguns pontos são destaque para a campanha S4, iniciada pela calça jeans, um dos grandes ícones das peças do vestuário. Dados levantados pela Mintel, em 2006, contabilizam a venda de 1,5 milhão de calças jeans no mundo, por ano. ${ }^{5} \mathrm{Um}$ produto tão difundido merece dar o start na campanha. Summer Rayne Oakes, na campanha green jeans emerge, dispara alertas contra as empresas predadoras e congratula-se com as conscientes, insistindo com dois valores para as indústrias de moda - consciência ecológica e integridade social. Os princípios da consciência ecológica são bastante difundidos e os da integridade social, anuviados, muitas vezes, pelo entusiasmo do consumidor em comprar produtos cada vez mais baratos. A integridade social da indústria é traduzida pelos principios: direito dos trabalhadores, trabalho e salário justos, melhor tratamento para a talentosa força de trabalho globalizada.

- Team minus 6\% é o movimento de um grupo de jovens japoneses que se debruçou sobre os hábitos de vestir, pensando em alternativas a fim de colaborar com 0 governo na meta de diminuir o consumo de energia (GARCIA, 2006). Uma das ideias de um grupo de jovens, que abalou o padrão de consumo e o uso da moda, foi aderir ao tradicional quimono japonês de algodão, mais leve e ventilado, como traje de trabalho no verão, em substituição ao terno, reduzindo assim o consumo de energia com ar-condicionado nos escritórios. As campanhas Warm Biz e Cool Biz, japonesas, tratam de divulgar o ecoconceito de uma nova forma de vestir para executivos e 
executivas, ou seja, "vestindo roupas da moda, quentes e confortáveis para o trabalho, dependendo menos dos sistemas de aquecimento", e o inverso vale para o verão, roupas bem leves e menos ar-condicionado. ${ }^{6}$ Nessa linha de pensamento, questiona-se 0 porquê de os americanos usarem o aquecimento interno de suas edificações em temperatura elevada durante o inverno. Se, assim como os japoneses, aderissem ao suéter de lã para o interior, em vez da manga de camisa, talvez fosse possível economizar energia que hoje é desperdiçada. Simples mudanças nos hábitos de vestir, sugeridas por jovens engajados ou por experts da moda também engajados, fariam a diferença. Ideias dessa natureza começam a se expandir pelo planeta, tentando minimizar problemas concretos e afetando o sistema da moda contemporâneo.

- Swap-0-Rama-Rama é uma prática de consumo consciente, iniciada em Nova York, em 2005, com o objetivo de incentivar as pessoas a se desfazerem do excesso de roupas e acessórios armazenados e em desuso, em defesa de um novo comportamento responsável e sustentável em relação ao consumo. A ideia é simples: elege-se um ponto de troca e customização de roupas, com tempo de funcionamento de 48 horas, por exemplo. Os interessados levam para o acervo as roupas que não querem mais; essas peças são expostas em araras e, aí, liberadas para troca. A roupa dispensada por um pode ser a desejada pelo outro. Estilistas e costureiras munidos de máquina de costura, papel, lápis, aviamentos, acessórios, retalhos, fitas, rendas etc. trabalham para fazer um upgrade de atualização na roupa resgatada. As negociações são previamente combinadas pela coordenação do evento. No fim, há um desfile, uma sessão de depoimentos e distribuição de etiquetas "100\% reciclado" (SILVA, 2008).

- A Osklen, em parceria com biólogos e ambientalistas, iniciou em 2000, mas ganhou autonomia somente em 2006, a e-fabrics, projeto que integra a e-brigate. A e-fabrics é uma chancela que identifica para o mercado as matérias-primas utilizadas pela indústria têxtil, que respeitam critérios de comércio justo e de desenvolvimento sustentável, tais como: a preservação da biodiversidade, o resgate de nossas tradições culturais e o controle do impacto do processo produtivo sobre o meio ambiente físico. A garantia e-fabrics é concedida a tecidos e materiais de origem sustentável em razão de cinco critérios: sustentabilidade da matéria-prima utilizada; impacto do processo produtivo no meio ambiente natural; resgate e preservação da diversidade e tradições culturais; fomento às relações éticas com comunidades e colaboradores; design e atributos comerciais.

- A Maxitex Indústria Têxtil, de Sapucaia do Sul, utiliza os resíduos de algodão das tecelagens e das malharias como matéria-prima para novos produtos. A empresa já produzia fios e tecidos utilizando garrafas pet. Mais recentemente, começou a desenvolver pesquisa com outras matérias-primas: o algodão é o reciclado da vez. Os resíduos de algodão são comprados das fábricas de Santa Catarina e destruídos pelo sistema de cardagem. Em seguida, é feito o emparelhamento das fibras, que são transformadas em fios de espessura larga sem uniformidade. Estes passam por um processo de estreitamento, chegando à espessura desejada. Cada peça de tecido reciclado é única, já que os fios que fazem o tecido são resultado de uma mistura de tons e espessuras diferentes, oriundas dos retalhos. Exclusividade, então, é agregada ao valor do produto reciclado (VISCARDI, 2009).

- Kato Jeans, Mizra e Sugar Cane, marcas de jeans japonesas cultuadas pelos jovens, fazem a tradição virar moda. Essas grifes não têm a ambição de expansão ilimitada ou de consumo ininterrupto incentivado pelas novidades estéticas sazonais. 0 valor cultivado embute conceitos de slow fashion, em que a sensibilidade, a dedicação, a tradição e os toques artesanais constituem o diferencial a ser percebido pelos clientes. 0 denim japonês usado nas marcas como Kato Jeans e Mizra distingue-se pelo uso de corante de tom azul profundo e é único no mundo, produzido nas cidades de Awa e Okayama. Além disso, é tecido em teares manuais. A Sugar Cane fabrica jeans de aspecto vintage, utilizando um processo que mistura cana-de-açúcar com o melhor selvage denim japonês. As peças são tingidas manual e individualmente $e_{\text {, }}$ para completar, são costuradas em máquinas antigas a fim de assegurar o aspecto envelhecido. Essas marcas de jeans de produção limitada têm a característica do luxo ligado à tradição (MADE in Japan, 2007-2008).

- Coopa-Roca é um projeto que busca integrar técnicas artesanais valiosas, das artesãs da Favela da Rocinha (RJ), aos processos industriais. Segundo depoimento da 
arte-educadora Tetê Leal, coordenadora executiva da Coopa-Roca: "O primeiro clique foi perceber que grande parte das mulheres da Rocinha são do Nordeste e dominam técnicas artesanais valiosas, o que nos levou a organizar a cooperativa. 0 segundo clique foi reconhecer na moda um mundo de oportunidades e ter consciência de que, para ampliar o impacto desse trabalho, era preciso associar as técnicas artesanais

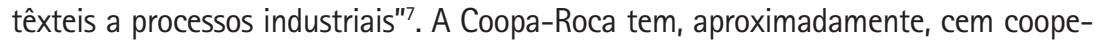
rativadas e desenvolve projetos em moda, design e arte, com parceiros como: Osklen, M. Officer e outros. ${ }^{8}$

Os alunos, sensibilizados com os cases de moda e sustentabilidade apresentados, envolveram-se na proposta da disciplina e aceitaram o desafio de desenvolver uma coleção com roupas usadas, advindas de coleta familiar ou mesmo compradas em brechós, reinventando o valor novidade, um dos fundamentos da moda.

A ideia trabalhada no primeiro brain storm foi acolhida por unanimidade. 0 conceito de reutilizar - que consiste em aumentar o ciclo de vida do produto dando a ele uma nova cara, uma nova finalidade - somado ao de reciclar - que é aproveitar o resíduo de um produto como matéria-prima para a produção de um novo - foram a base para o desenvolvimento do trabalho. Iniciar um projeto de coleção, partindo de peças prontas, requer um olhar acurado para a seleção das peças a serem reutilizadas. A facilidade de retomar uma peça pronta, que tem um bom corte, um bom tecido, marca de qualidade, é compensada pela limitação das escolhas. $\mathrm{Ou}$ seja, na reutilização de roupas são poupadas as tarefas de modelar e montar a peça; em compensação, a liberdade de escolha das matérias-primas e da forma é restrita. 0 trabalho de reutilização tem seus cuidados específicos e aí reside o desafio até então não-experimentado pelos alunos do curso de Moda e também a razão da pergunta: Repense: a moda pode ser sustentável?

\section{2ํㅡㄹ Encontro: sensibilização}

Os alunos tomaram contato com The story of stuff(A história das coisas) ${ }^{9}$, um documentário idealizado por Annie Leonard - ativista que passou os últimos dez anos viajando ao redor do mundo e lutando em defesa do meio ambiente -, e defrontaram-se com as seguintes questões: De onde vieram e para onde vão todas as coisas que compramos, que temos e que consumimos? Por que as pessoas consomem tanto? 0 que há por trás dessa história toda?

Leonard argumenta que os verdadeiros custos de extração, produção, distribuição, consumo e descarte dos bens produzidos não aparecem nos livros de contabilidade, pois eles são relativos à vida, não só das pessoas, mas de todas os seres vivos do planeta. Da extração da matéria-prima, passando pela produção dos produtos, até sua venda e, finalmente, o descarte, são etapas que compõem o ciclo de vida dos produtos, afetam comunidades locais e mundiais, apesar de muitas dessas etapas passarem longe da vista humana aparentemente civilizada.

The story of stuff revela, de forma rápida, atos, fatos e dados da intervenção humana no planeta, transformando-os em bens de consumo que, por sua vez, estão exaurindo o planeta, sem a mínima consciência de sustentabilidade; aponta links entre assuntos ambientais e sociais; e faz um alerta a todos os cidadãos, independentemente da nacionalidade, de modo a criarem um mundo mais justo e sustentável. The story of stuff leva o espectador a um tour provocativo; abre os olhos para o entendimento dos custos reais da cultura em que vivemos, guiada pelo consumo; e mostra o que acontece desde a extração dos recursos naturais até a incineração de um iPod, quando ele vira lixo (RIGATTI et al., 2008).

Oportuno lembrar que desenvolvimento sustentável significa atender às necessidades do presente sem comprometer a capacidade das gerações futuras de atenderem as suas. Tecnicamente falando, desenvolvimento sustentável, segundo Dobrovolski (2004), é o processo de produção que pensa eficiência econômica, sustentabilidade ambiental e sustentabilidade social, sendo assim: 
- a eficiência econômica é medida pela análise dos processos produtivos, considerando as tendências de maior geração de benefícios com o menor uso de recursos;

- a sustentabilidade ambiental implica a definição de limites de uso dos recursos naturais, para evitar sua exaustão, e a superação da capacidade de suporte dos ecossistemas;

- a sustentabilidade social envolve a distribuição dos impactos de políticas públicas e 0 acesso a recursos e serviços, a justiça dessas distribuições, a remuneração justa do trabalho, bem como suas condições legais, os níveis de saúde das comunidades e o padrão de oportunidade das pessoas.

Nesse encontro, os alunos combinaram que para a aula seguinte todos deveriam trazer roupas em desuso (limpas e em bom estado), aviamentos, retalhos de tecidos e acessórios, para iniciar a proposta de coleção. A fonte de busca dessas peças seriam roupas pessoais, de familiares ou até mesmo adquiridas em brechós, contanto que pudessem ser reutilizadas.

Foi também nomeada a aluna relatora ${ }^{10}$, responsável por disponibilizar as decisões no site da UCS, no diário online da disciplina.

\section{3ำ Encontro: formalização e administração do projeto}

Objetivo geral

- colocar em prática as etapas de desenvolvimento de produto de moda para o lançamento de minicoleções, utilizando conceitos de sustentabilidade, como reutilizar e reciclar roupas em desuso, retalhos, acessórios e aviamentos.

Objetivos específicos

- estender o ciclo de vida de produtos de moda reciclando peças usadas oriundas de amigos e familiares, brechós e doações de empresas;

- experimentar as possibilidades do mercado de reciclados na moda do vestuário;

- ampliar o conceito de criação em moda a partir da reutilização de roupas usadas;

- aprender a trabalhar em equipe, planejando, organizando e dividindo tarefas para atingir um objetivo comum;

- abrir espaço para o desenvolvimento de lideranças nas equipes;

- dar liberdade para aflorarem iniciativas, ideias e diálogo dentro da equipe;

- conhecer instituições sociais da cidade e levantar formas de atendê-las econômica e emocionalmente.

Desenvolvimento

Por decisão da turma, as roupas reunidas foram selecionadas e agrupadas por cor, depois penduradas numa corda, para visualização do conjunto. Iniciou-se uma discussão de como atingir o objetivo do projeto, de forma organizada e com bons resultados. 0 próximo passo foi a divisão de equipes, por afinidade ou preferência por cor. Cada grupo assumiu uma cor e pensou num detalhe a ser utilizado como elo para formar as familias. Esse detalhe teve duas funções: primeiro, dar um ar de renovação necessário às peças; e, segundo, dar unidade visual à coleção, pensando no desfile e nas entradas em passarela. Foi organizado o banco de materiais (tecidos diversos, retalhos, botões, ilhoses, fivelas, rebites, fitas, tigrados, zebrados, rendas, couro, flores e outros) para ser explorado nos reaproveitamentos. Cada grupo assumiu a tarefa de desenvolver, no mínimo, cinco peças, passando pelas etapas básicas do desenvolvimento de coleção: desenho, sugestão de materiais, quadro de coleção, montagem, ficha técnica, correção, preço de venda e lançamento.

Algumas peças foram ajustadas, outras enriquecidas com detalhes, outras totalmente transformadas, utilizando-se apenas o tecido da peça. Saia virou blusa, gravatas foram transformadas em vestido e vestido em saia etc. Foram ajustes, misturas e restaurações, com resultados surpreendentes.

Um brain storm coletivo levantou nomes possíveis para cada família-cor, a saber: Natural; Fênix; Casulo; Metamorfose; 7o Dia; Camaleão; Reciclagem; Terra; Ar; Vento; Água; Fogo; Águia; e Butterfly. ${ }^{11}$

Foi um encontro marcado pela excelente participação dos alunos. Diferentes pontos de vista foram discutidos até chegarem a um consenso. Cada grupo escoIheu um coordenador. Algumas questões foram lançadas para reflexão até o próximo encontro: 0 que fazer com as coleções depois de prontas? Quando e onde lançar as 
coleções? Mostrar as peças em araras? Fazer desfile? Vender? Para quem? Qual é o público-alvo? Alunos do Centro de Artes e Arquitetura? Algumas tribos da cidade? 0 que fazer com o resultado das vendas?

\section{4ํㅡㄹ Encontro: planejamento e cronograma de atividades}

Respondendo a essas questões, alguns alunos eram da opinião de que a coleção deveria ser desfilada no próprio campus da universidade, especialmente pelas facilidades de logística; outros sugeriram que as coleções fossem desfiladas num café mais alternativo da cidade - o Zarabatana Café - do Centro Municipal de Cultura Henrique Ordovás, para dar maior visibilidade aos alunos e ao curso e aumentar a participação do público na campanha. Apesar das dificuldades na organização, os alunos decidiram pela segunda opção (RIGATTI et al., 2008).

Outras decisões: as coleções seriam vendidas logo após o desfile, e o resultado das vendas reverteria para uma obra social. 0 desfile-bazar, como passou a ser chamado, ficou marcado e aconteceu no dia 19 de novembro de 2008.

Dois tipos de obra social foram lembrados para encaminhar os resultados: casa para idosos e creche para crianças. A escolhida foi a Casa Abrigo Sol Nascente, instituição municipal que recebe crianças de 0 a 12 anos, abandonadas ou vítimas de maus-tratos.

Com a data de lançamento determinada, foi elaborado pelo grupo o cronograma gerencial nos moldes do utilizado na disciplina Gerência de Produto de Moda.

Cronograma

Desenvolvimento de Coleção Restaurada/Reciclada

\begin{tabular}{|c|c|c|c|c|c|c|c|c|c|c|c|c|}
\hline ATIVIDADE/MÊS & \multicolumn{2}{|c|}{ SET } & \multicolumn{4}{|c|}{ OUT } & \multicolumn{4}{|c|}{ NOV } & \multicolumn{2}{|c|}{ DEZ } \\
\hline SEMANA/MÊS & 3 & 4 & 1 & 2 & 3 & 4 & 1 & 2 & 3 & 4 & 1 & 2 \\
\hline Encontros & & 1 & 2 & 3 & 4 & 5 & 6 & 7 & $8 / 9$ & 10 & 11 & 12 \\
\hline Case e Cases & & $\bullet$ & $\bullet$ & & & & & & & & & \\
\hline Vídeo: The story of stuff & & & $\bullet$ & & & & & & & & & \\
\hline Temas/famílias/cores & & & & $\bullet$ & & & & & & & & \\
\hline Equipe e liderança & & & & $\bullet$ & & & & & & & & \\
\hline Escolha de peças para reciclar & & & & $\bullet$ & $\bullet$ & & & & & & & \\
\hline Escolha do link temático & & & & $\bullet$ & $\bullet$ & & & & & & & \\
\hline Cronograma de atividades & & & & & $\bullet$ & & & & & & & \\
\hline Desenhos & & & & & $\bullet$ & & & & & & & \\
\hline Microvariações & & & & & $\bullet$ & & & & & & & \\
\hline Definição: evento/data/formato & & & & & $\bullet$ & & & & & & & \\
\hline Evento/nome & & & & & $\bullet$ & & & & & & & \\
\hline Release/divulgação & & & & & & & $\bullet$ & & & & & \\
\hline Evento/flyer & & & & & & & $\bullet$ & & & & & \\
\hline Manufatura & & & & & $\bullet$ & $\bullet$ & $\bullet$ & $\bullet$ & $\bullet$ & & & \\
\hline Ficha técnica & & & & & & & $\bullet$ & $\bullet$ & & & & \\
\hline Etiqueta embalagem & & & & & & & & $\bullet$ & $\bullet$ & & & \\
\hline Preço & & & & & & & & & $\bullet$ & & & \\
\hline Evento/definição/tarefas & & & & & & & & $\bullet$ & & & & \\
\hline Evento/divulgação & & & & & & & $\bullet$ & $\bullet$ & $\bullet$ & & & \\
\hline Evento/trilha sonora & & & & & & & & $\bullet$ & $\bullet$ & & & \\
\hline Evento/modelos/prova & & & & & & & & & $\bullet$ & & & \\
\hline Lançamento e venda & & & & & & & & & $\bullet$ & & & \\
\hline Avaliação do desfile & & & & & & & & & & $\bullet$ & & \\
\hline Organização da festa & & & & & & & & & & $\bullet$ & & \\
\hline Levantamento/brindes & & & & & & & & & & $\bullet$ & & \\
\hline Acerto de contas & & & & & & & & & & $\bullet$ & & \\
\hline Relatório escrito & & & & & & & & & & & $\bullet$ & \\
\hline Festa Casa Abrigo Sol Nascente & & & & & & & & & & & & $\bullet$ \\
\hline
\end{tabular}


Notou-se que algumas atividades listadas no cronograma eram de decisão e execução do grande grupo, e outras, das equipes responsáveis pelas minicoleções. Dessa forma, os alunos foram vivendo a experiência de gestão por objetivos, distribuindo as responsabilidades, exercendo liderança, descobrindo habilidades, cumprindo prazos e pensando no bom desenvolvimento do trabalho como um todo.

Desde o terceiro encontro, as equipes foram desenhando as peças e propondo as microvariações ${ }^{12}$ no papel, ou seja, conforme orientação de Abranches e Brasileiro Júnior (1990), antes de fazer um protótipo e, nesse caso, antes de reformar uma peça, são necessários vários desenhos com diferentes detalhes para facilitar a escolha. As peças começaram a ser reutilizadas e recicladas a partir do quarto encontro; esse trabalho foi organizado e desenvolvido pela equipe, porém, a cada encontro, era submetido ao grande grupo para sugestões.

Surgiram novas questões: Onde reformar as peças? Que tipo de apoio poderia ser dado pelo curso? Nome do desfile-bazar? Tipo de ingresso para o desfile-bazar? Como e onde divulgar o desfile-bazar?

\section{5o Encontro: reciclagem e logística}

A oficina de costura do curso ficou disponivel para os alunos trabalharem e, além de receberem auxilio da técnica da oficina, foram orientados por professores na modelagem.

Os materiais necessários para o desfile (trilho vermelho para demarcar a passarela, banners, espelhos, iluminação, araras, cabides), seu transporte e a impressão dos folders de divulgação foram disponibilizados pelo diretor do Centro de Artes e Arquitetura.

Várias sugestões foram dadas em relação ao ingresso do desfile-bazar, como: um quilo de alimento não perecível, brinquedos e fraldas descartáveis. Em consulta à coordenação da Casa Abrigo Sol Nascente, ficou acordado que melhor seriam brinquedos, já que se aproximava o Natal.

Depois de brain storm do grande grupo, foram enumerados alguns nomes para o desfile-bazar, como: Solidariedade sustentável; Solidariedade fashion; Moda solidária; Moda: solidariedade sustentável; Moda S2: solidariedade sustentável; A moda pode ser sustentável?; Repense: a moda pode ser sustentável? Este último foi escolhido por unanimidade.

Alguns alunos se prontificaram a trazer para a aula seguinte sugestões para flyer de divulgação e release para imprensa.

\section{6ํㅡㄹ Encontro}

0 release para a imprensa e o flyerpara a divulgação foram apresentados e aprovados pelo grande grupo. 0 release, ilustrado com fotos dos alunos em atividade, enviado à Assessoria de Comunicação da UCS, para jornais da cidade e para a UCS TV, rendeu dois espaços em coluna do jornal O Pioneiro e um programa na UCS TV.

O Flyer ${ }^{13}$

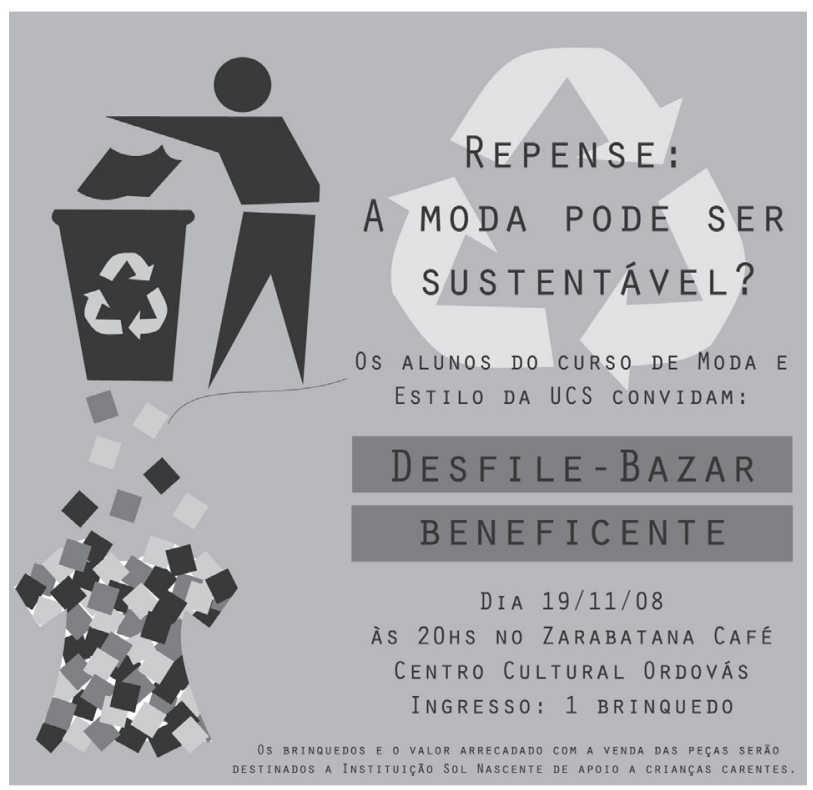




\section{Encontro: designação de equipes para logística do desfile-bazar}

As roupas para o desfile continuavam a ser recicladas e avaliadas pelo grupo. As avaliações consistiam de prova das peças, correção e modificações quando sugeridas e aprovadas. Nesse encontro, o assunto central do grande grupo foi: o planejamento, a organização e a distribuição de tarefas para o desfile-bazar. As tarefas foram listadas com os respectivos responsáveis pela sua realização, assim determinadas:

- contato com os proprietários do Zarabatana Café e levantamento de necessidades, como passarela, camarins, araras e mesas para bazar, cesto para recebimento dos brinquedos, áudio e iluminação;

- materiais para confecção das etiquetas e das embalagens. 0 material plástico foi descartado por não ser biodegradável. Optou-se pela utilização de TNT nas embalagens e morim nas etiquetas. Um carimbo, com o símbolo da sustentabilidade e o nome do projeto: Repense: a moda pode ser sustentável?, foi confeccionado com o objetivo de criar uma marca para os produtos reciclados;

- confecção das etiquetas (tags) e embalagens;

- base de cálculo para o preço e preços de venda;

- seleção dos manequins e prova final;

- organização das entradas em passarela, a harmonia dos looks e as famílias-cor;

- divulgação do evento em jornais, TV, entre os alunos do Centro de Artes e Arquitetura;

- maquiagem e cabelo das manequins;

- etiquetagem das peças para o bazar;

- recepção no Zarabatana Café;

- áudio para o desfile;

- vendas.

\section{8o Encontro: atividades pré-evento}

Esse encontro aconteceu às vésperas do desfile. Apesar do grande número de atividades a serem executadas, mencionadas anteriormente, os trabalhos desenvolveram-se com eficiência e responsabilidade, principalmente porque o grupo havia planejado, organizado e determinado os responsáveis no encontro anterior.

Cabe salientar que, após cada grupo calcular os preços das peças de suas minicoleções, o grande grupo revisou todos os preços para verificar se havia coerência entre eles. Com as peças prontas, foi possivel ao grupo observar que a aparência dos produtos era importante para o estabelecimento do preço; alguns produtos podiam ter uma margem de contribuição maior enquanto outros estavam no limite.

\section{9o Encontro: desfile-bazar}

Tudo ocorreu conforme o combinado: os alunos chegaram com duas horas de antecedência no Zarabatana Café. Cada aluno fez sua parte, portanto, não houve imprevistos ou correrias. Passarela, iluminação, som, roupas organizadas em araras, com o nome da manequim e o número de entrada, cabelo e maquiagem sendo feitos, casa cheia, holofotes etc.

0 café lotou, algumas mesas precisaram ser acrescentadas para acomodar as pessoas. 0 desfile teve início com entradas individuais, looks bem compostos e minicoleções, nomeadas em definitivo e bem identificadas com o elo que alinhavava todas as peças da coleção. A saber: coleção Black Romântico (preto e flores coloridas, bi ou tridimensionais); Camaleão (estampados); Black Metal (preto e detalhes com fita acetinada nas cores néon); Butterfly (jeans, tule e estampado em tons de azul); Areia (tecidos crus, com detalhes em malha retilínea, e estampado em tons terra). Vendeu-se em torno de $85 \%$ das peças. Aproximadamente 50 brinquedos foram arrecadados. 


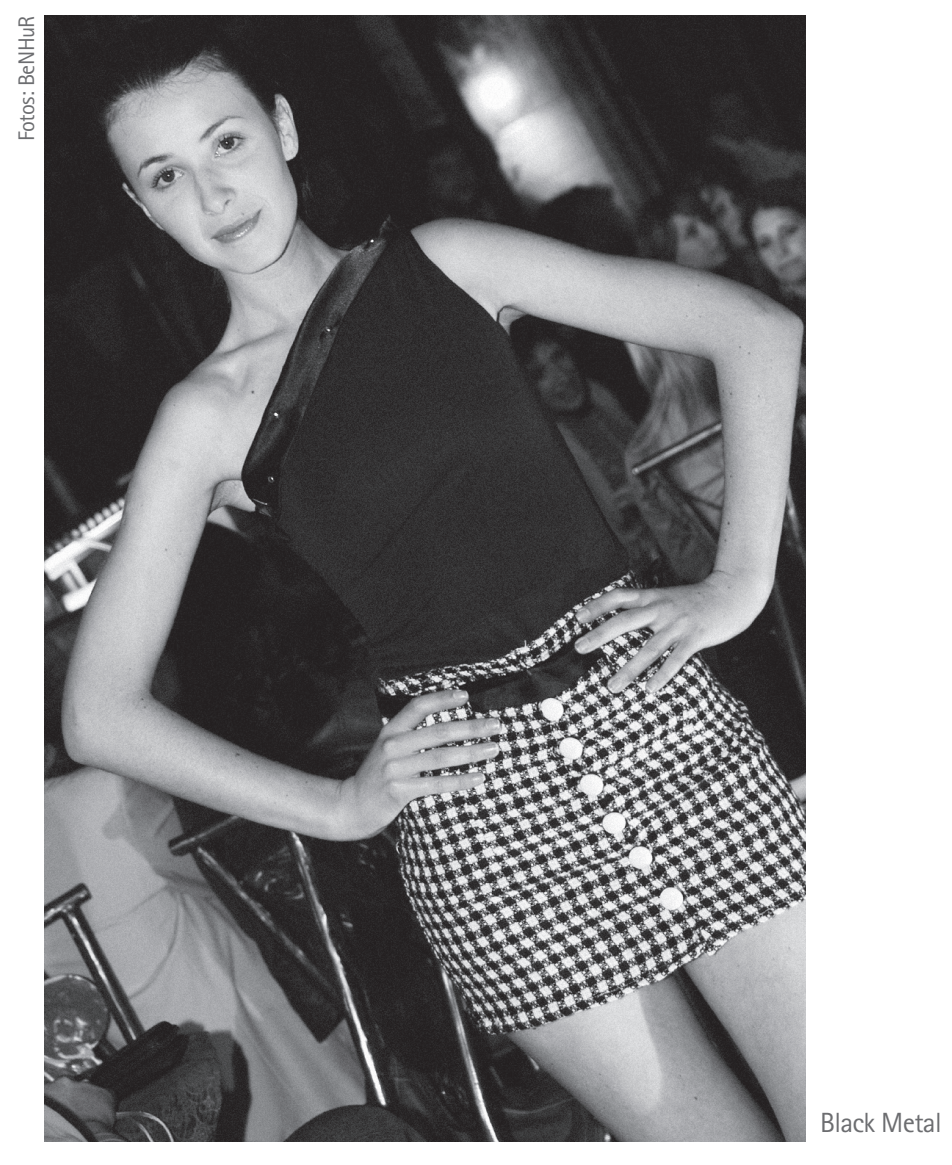

[82

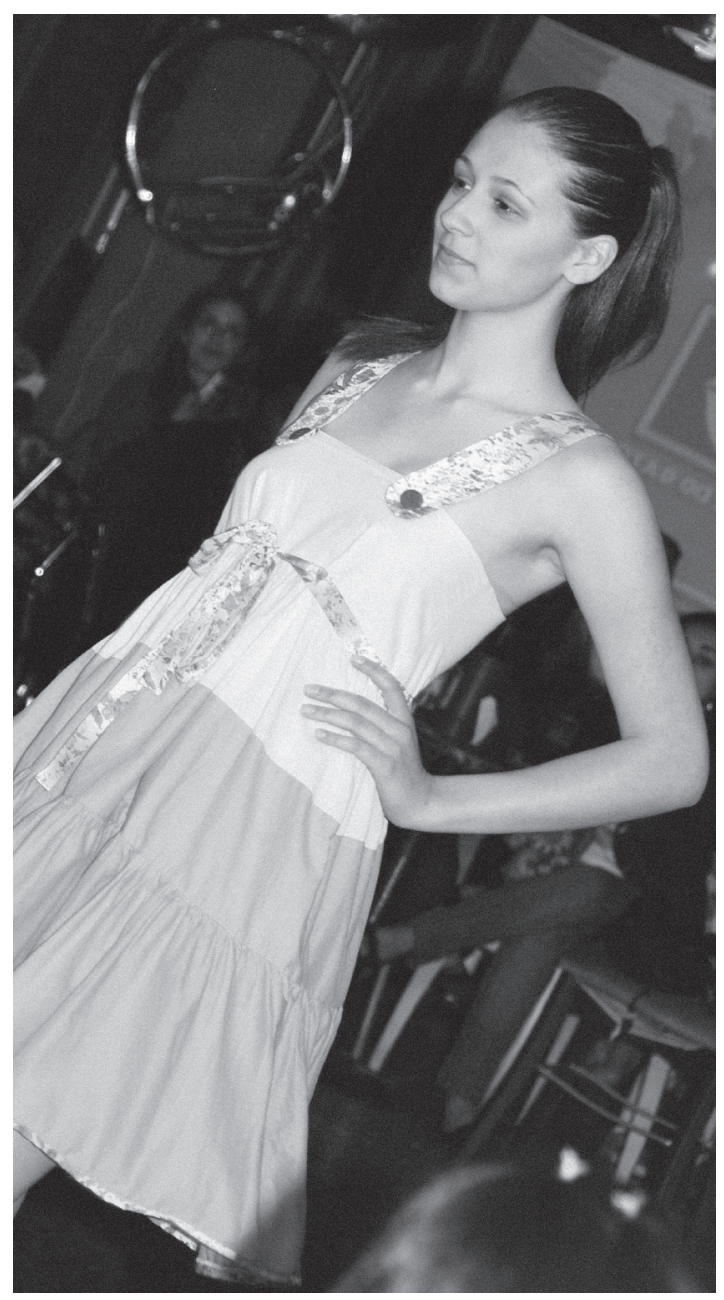



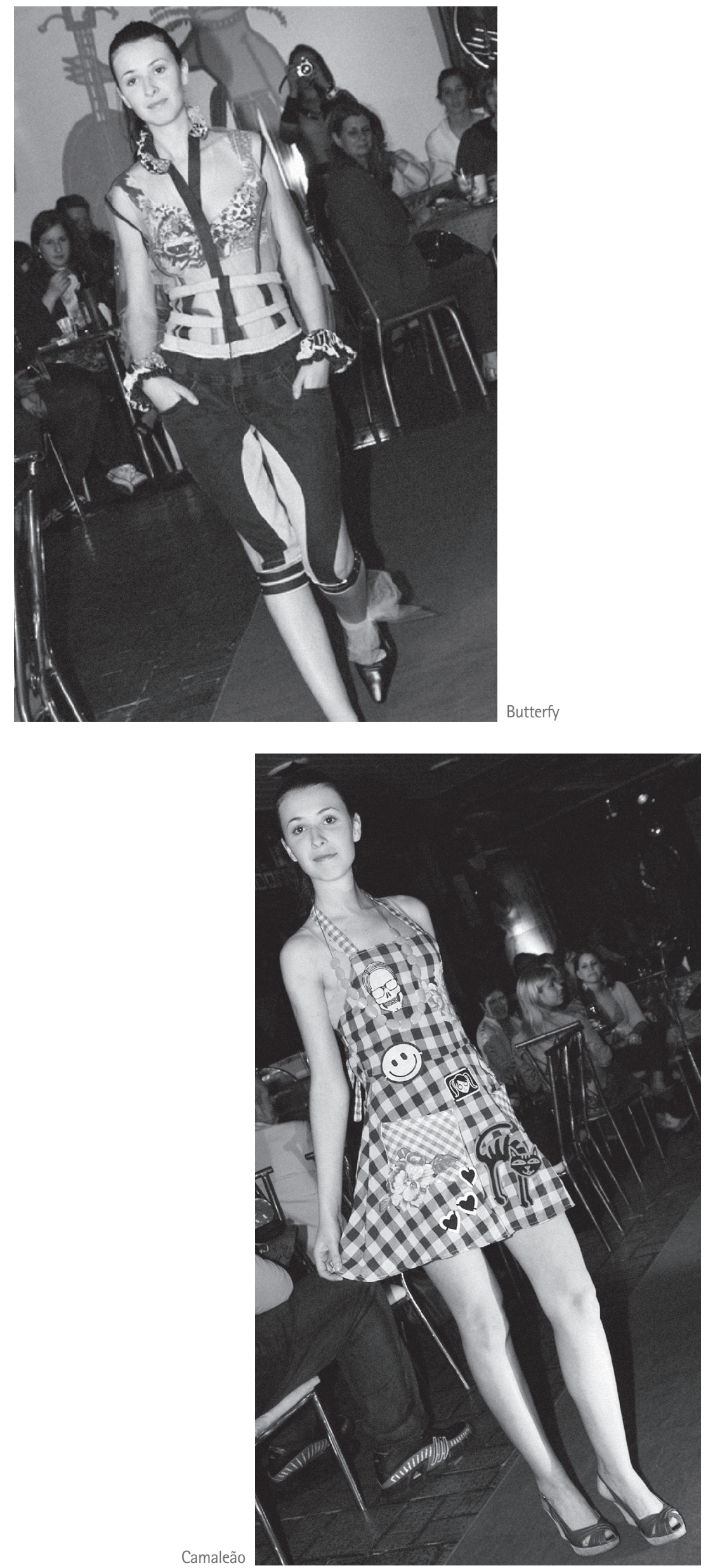
10ำ Encontro: contabilizando os resultados e organizando o seu destino

Seleção e embalagem dos presentes arrecadados de acordo com a idade e o sexo das crianças. Acerto de contas e determinação da utilização do resultado. As verbas foram destinadas para um lanche festivo, com as 40 crianças da casa, para a compra ${ }^{14}$

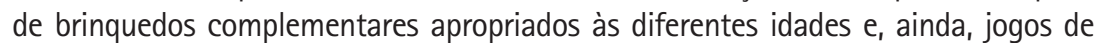
lençóis, atendendo à necessidade indicada pela coordenadora da Casa Abrigo. Nesse encontro determinou-se a divisão de tarefas para a festa (compra de salgadinhos, refrigerantes, presentes etc.) e os respectivos responsáveis.

\section{1ํㅡㄹ Encontro: relatório e feedback}

Trabalho em grupo para realização do relatório de cada equipe, como conclusão do case, relatando o desenvolvimento dos trabalhos, as dificuldades, a colaboração dos membros, o cumprimento das tarefas de acordo com o cronograma elaborado, a avaliação da proposta como um todo e a autoavaliação.

\section{2ํㅡㄹ Encontro: comemoração solidária}

Entrega dos trabalhos escritos e avaliação oral do desempenho dos alunos e das equipes durante os dois meses dedicados ao projeto. Depoimentos, pontos positivos $\mathrm{e}$ pontos negativos, dificuldades, facilidades.

A festa foi realizada no último dia de aula na Casa Abrigo Sol Nascente, com a presença de $90 \%$ dos alunos.

\section{Considerações finais}

0 trabalho proposto atingiu seus objetivos de forma muito positiva, pois o empenho da maioria dos alunos manteve-se alto desde o início das tarefas até a sua conclusão. ${ }^{15}$ Entre os resultados podemos apontar:

- apreensão dos conteúdos da disciplina, facilitada pelo exercício paralelo da gestão por objetivo e assumida pelas equipes e pelo grande grupo, no desenvolvimento de minicoleções de moda;

- 0 entendimento de sustentabilidade, descobrindo possibilidades de prolongar 0 ciclo de vida do produto de moda que, no seu fundamento, é programado para a "obsolescência percebida", ou seja, trata-se do produto fora de moda ou da estação passada, que foi depreciado pelas novidades; uma prática comum da sociedade de consumo, em que o velho, mesmo que em bom estado, é descartado para evitar constrangimentos;

- a solidariedade com os menos afortunados, concretizada na presença da maioria dos alunos na festinha de Natal, realizada na Casa Abrigo Sol Nascente, para as crianças de 0 a 12 anos que sofrem maus-tratos ou foram abandonadas pelos pais.

- responsabilidade, comprometimento, pontualidade, capacidade de trabalhar em equipe, colaboração, empenho, solidariedade por parte dos alunos. 


\section{NOTAS}

${ }^{[1]} \mathrm{Em}$ 2000, Oskar Metsavaht, diretor de criação da Osklen, fundou juntamente com outros profissionais o movimento e-brigade de educação ambiental. Para mais informações, veja: <http://www.e-brigade.org>.

${ }^{[2]}$ Veja também: <http://www.e-fabrics.com.br>.

${ }^{[3]}$ De dezembro de 2007 a 15 de fevereiro de 2008, o canal da internet de notícias e informações de moda e arte Showstudio, fundado e dirigido pelo próprio Knight, recebeu essas produções. Disponível em: $<$ http://www.showstudio.com/project/politicalfashion>. Acesso em: 2 maio 2009.

${ }^{[4]}$ Chamou atenção de Summer Rayne Oakes o filme China blue, dirigido por Micha Peled, que retrata a exploração da mão de obra adolescente na China como, por exemplo, Jasmine (16) e Orchid (14) flagradas com prendedores de roupa nas pálpebras para não cochilar durante o trabalho. Disponível em: <http:// www.teddybearfilms.com/chinablue>. Acesso em: 2 maio 2009. Mais informações sobre a atuação de Oakes disponiveis em: <http://www.summerrayne.net>.

${ }^{[5]}$ Disponivel em: <http://www.summerrayne.net/index.php/2007/04/02/caught-with-our-pants-down-s4-the-denim-issue>. Acesso em: 2 maio 2009.

${ }^{[6]}$ Disponivel em: <http://www.env.go.jp/en/press/2005/0826a.html>. Acesso em: 2 maio 2009.

${ }^{[7]}$ Visão que constrói. Agenda Sudameris, 2007. Concepção: Thymus Branding e Scriba Comunicação Corporativa.

${ }^{[8]}$ Disponivel em: <http://www.coopa-roca.org.br>. Acesso em: 2 maio 2009.

${ }^{[9]}$ A animação The story of stuff (A história das coisas) com duração de 20 minutos, tem roteiro e apresentação de Annie Leonard, direção de Louis Fox e produção de Erica Priggen. Desde 4 de dezembro de 2007 está disponivel em: <http://www.storyofstuff.com/international>.

[10] Juliana Sinnot foi a relatora.

${ }^{[11]}$ Fênix, Casulo, Camaleão e Butterfly eram os nomes preferidos naquele momento.

${ }^{[12]}$ As microvariações pressupõem o conceito de planejar, isto é, levantar muitas opções para escolher a melhor. Segundo Koontz; O'Donnell; Weirich $(1986$, p. 5) "se apresento apenas uma opção para escolher um caminho, ela provavelmente não será a melhor".

${ }^{[13]}$ Desenvolvido pela aluna Manuela Horn.

${ }^{[14]}$ Alunos responsáveis pela compra dos brinquedos: Daniel Rigatti e Gabriela Sonaglio.

${ }^{[15]}$ Importante ressaltar que sem o entusiasmo dos alunos este trabalho não seria possivel. Meus cumprimentos e agradecimentos a Adriana Fantinel, Alessandra Chiele, Ana Carolina Tisott, Camila F. Spricigo, Camila T. Wagner, Carolina Loss, Carolina R. Sehbe, Claudia Andreazza, Claudia de Oliveira, Cristina G. Esteves, Daiane T. Rizzon, Daniel Rigatti, Danubia Pasa, Everton A. Pedroso, Franciele Righêz, Gabriela Pessoli, Gabriela Sonaglio, Jordana Vergani, Juliana Sinnott Lima, Manuela Horn, Maria Cristina Schuster, Maríndia Elisabeth C. Felix, Nathália B. Raphaelli, Renata F. Meirelles, Renata R. Ceccato, Rosangela M. Faedo, Ruth G. Ristow, Sandramara Chiele, Soleide M. Ritter, Viviane Perottoni e Zoraia S. Lahude.

\section{REFERÊNCIAS}

ABRANCHES, Gerson P.; BRASILEIRO JÚNIOR, Alberto. Manual da gerência eficaz de confecção. Rio de Janeiro: SENAI/DN: SENAI/CETIQT, 1990.

DOBROVOLSKI, Ricardo L. Perfis de desenvolvimento sustentável: quantificação e análise espacial para o Rio Grande do Sul. In: ROMEIRO, Ademar Ribeiro. Avaliação e contabilização de impactos ambientais. Campinas: Unicamp, 2004.

FARREN, Anne; HUTCHISON, Andrew. Ciborgues, novas tecnologias e o corpo: a natureza mutável do vestuário. Fashion Theory, São Paulo, Anhembi Morumbi, v. 3, nº 4, dez. 2004.

GARCIA, Carol. Cultura de moda na berlinda, São Paulo, 2006. World Fashion, p. 6; 48, jan.-fev. 2006, entrevista concedida a Cilene de Castro.

KOONTZ, Harold; O'DONNELL, Cyril; WEIRICH, Heinz. Administração: planejamento, organização e controle. São Paulo: Pioneira, 1987, v. 2.

LIPOVETSKY, Gilles. Império do efêmero: a moda e seu destino nas sociedades modernas. São Paulo: Companhia das Letras, 1989.

MADE in Japan: um segredo de sucesso. UseFashion, ano 4, nº 47, dez. 2007-jan. 2008.

MAU, Bruce. Massive chance. Chicago: Phaidon, 2006.

RIGATI, Daniel et al. Repense: a moda pode ser sustentável? Relatório dos alunos da equipe CAMALEÃO. Semestre 2008.2. Curso de Tecnologia em Moda e Estilo. Universidade de Caxias do Sul.

SILVA, Adriana. Corte e costure. Spot, Caxias do Sul, Eberle Fashion, ano 5, no 11, p. 92-95, ago. 2008.

VISCARDI, Karen. Inovação: lixo se transforma em moda. Jornal do Comércio, Porto Alegre, 30 jan. 2009. Caderno de Economia, p. 8. 